\title{
Congenital spinal deformity in a three generation family
}

\section{K TEMPLE*, T G THOMAS $\dagger$, AND M BARAITSER $\ddagger$}

From * the Department of Paediatric Genetics, Institute of Child Health, 30 Guilford Street, London WC1N $1 E H ; †$ †uckland Hospital, Coombe Valley Road, Dover, Kent; and †The Hospital for Sick Children, Great Ormond Street, London WC1N 3JH.

SUMMARY Short stature resulting from spinal deformity in three generations of a family is reported. Multiple vertebral anomalies were found in the proband and are the probable underlying cause of the severe scoliosis seen in the adult members.

The pattern of inheritance suggests that an autosomal dominant gene is responsible for this condition, but it may well be the same gene that causes the dominant form of spondylocostal dysostosis, this family representing one end of the spectrum with mild rib changes.

The clinical features of spondylocostal dysostosis are reviewed.

Multiple vertebral anomalies are more common in first degree relatives of affected subjects, ${ }^{1}$ but few pedigrees have been reported suggesting an autosomal dominant pattern of inheritance.

Mendelian inheritance has been postulated in families with vertebral malformations associated with rib anomalies. These are described under various headings but most commonly as 'spondylocostal dysostosis'. These are mostly recessively inherited $^{2-7}$ and so few dominant families are recorded in detail ${ }^{89}$ that the full range of findings in this latter condition is unknown.

A three generation family with severe vertebral

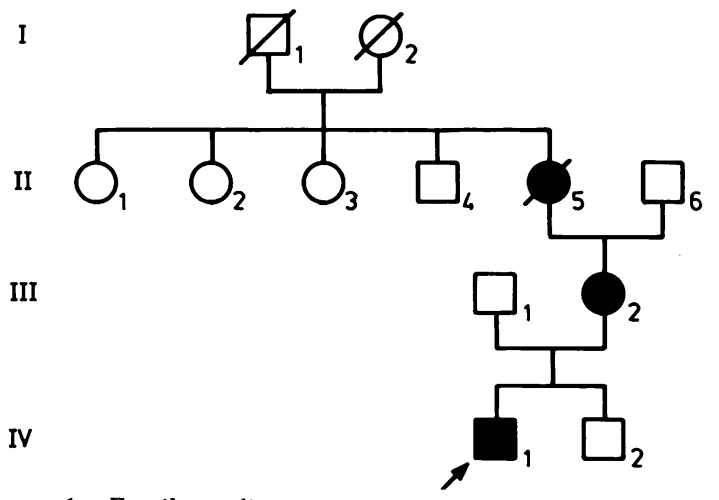

FIG 1 Family pedigree.

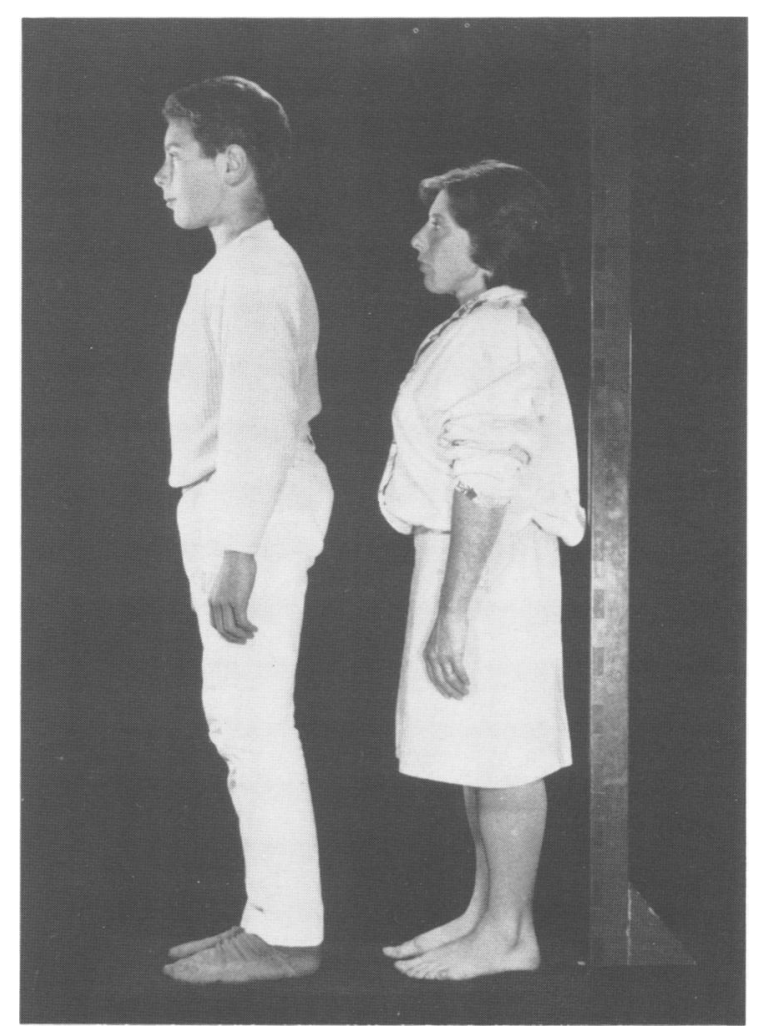

FIG 2 Patient 1 (IV.1) at 14 years (height $149.6 \mathrm{~cm}$ ) and patient 2 (III.2) at 33 years (height $136.5 \mathrm{~cm}$ ) showing short stature. 
changes resulting in short stature and scoliosis is described. There are many features in common with the previously reported families with dominantly inherited spondylocostal dysostosis, but deformity in this family is limited to the spine with relative sparing of the ribs.

\section{Case reports}

Detailed information is available on two of the members of this family. The pedigree is shown in fig 1 .

PATIENT 1 (IV.1)

Patient 1 was born on 11.5.73 and was referred at the age of 14 years to the genetic clinic with short stature (fig 2). He was born by caesarian section because of cephalopelvic disproportion, weighing $2800 \mathrm{~g}$. Soon after birth he was noted to have bilateral inguinal herniae but was thought to be otherwise normal.

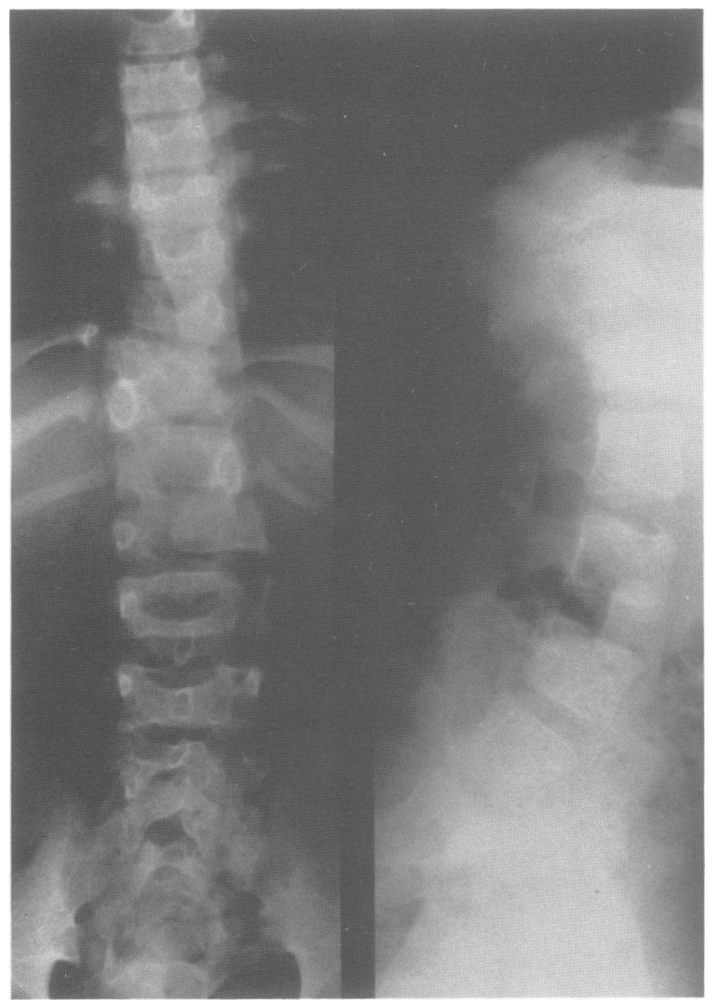

FIG 3 Spinal $x$ ray (AP and lateral) of IV.1 showing partial fusion of $T 8$ and $T 9$, absent right pedicle of $T 9$, fusion of T10 and T11 with absent left sided pedicles, fusion of T12 and L1 with absent right sided pedicle of T12 and left sided pedicle of $L 1$, and absent left pedicle of $L 2$.

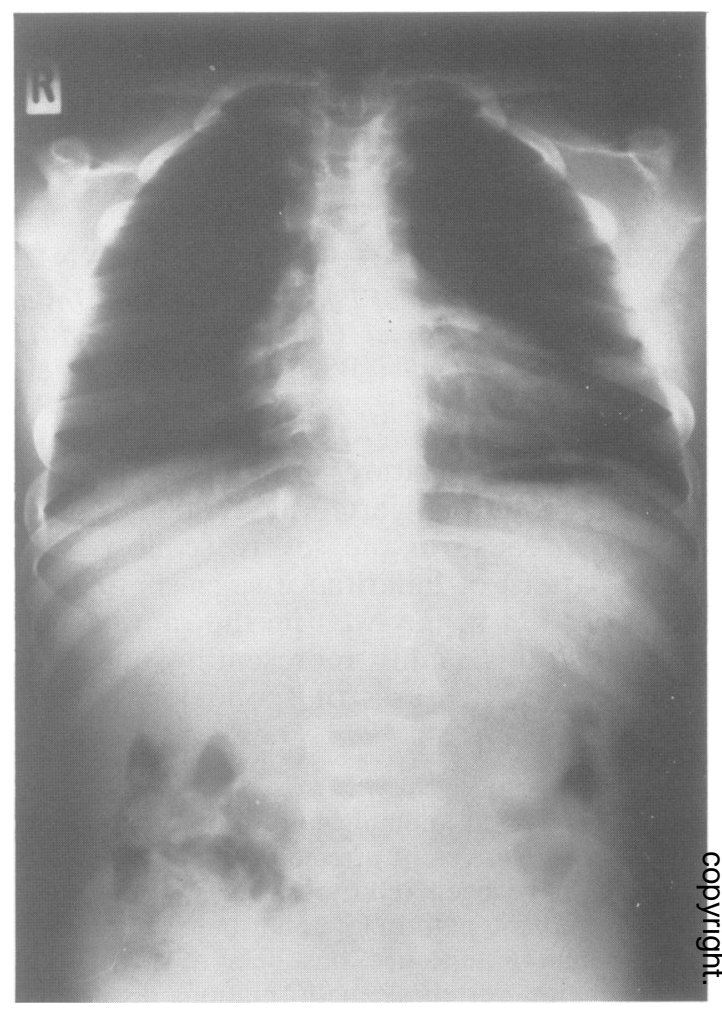

FIG 4 Chest $x$ ray of IV.I showing multiple vertebral anomalies but relative sparing of the ribs.

By the age of three years his parents were concerned about his short stature. He has been followed carefully since but required no medical intervention. Intelligence is normal.

Examination at 14 years of age showed height $149.6 \mathrm{~cm}$ (3rd centile), weight $47.5 \mathrm{~kg}$ (50th centile), head circumference $55 \mathrm{~cm}$ (50th centile), sitting 8 height $75 \cdot 3 \mathrm{~cm}(-3 \mathrm{SD})$, and upper to lower height ratio 1.01 (mean 1.11 for age). He had a marked 을 lumbar lordosis but no scoliosis. Spinal movements were full. Neurological examination was normal.

Chromosome analysis was normal, $46 \mathrm{XY}$. $X$ rays of the spine and chest showed multiple vertebral o anomalies from the mid-thoracic level distally (fig $N$ $3)$. The changes included fused vertebrae and $\underset{\omega}{\mathrm{N}}$ several absent vertebral pedicles. There was relative sparing of the thoracic vertebrae. Twelve ribs were present bilaterally but the posterior end of the left $\frac{}{\overparen{D}}$ 11 th rib was unusually slender and showed an $\stackrel{?}{?}$ abnormal costovertebral joint. This corresponds to 0 the area of fusion of T10 and T11 (fig 4). Congenital deformities of the sacrum were present. 
Patient 1 has a 12 year old brother of normal height, $148 \cdot 3 \mathrm{~cm}$ (50th centile). He has normal spinal $x$ rays. Their father is $180 \mathrm{~cm}$ tall and said to be normal. He has not been examined formally.

\section{PATIENT 2 (III.2)}

Patient 2 was born on 14.4 .54 and is the 33 year old mother of patient 1 (fig 2). She is unsure of her early childhood details but has been shorter than her peers throughout her life. Scoliosis was first noted at the age of 14 when she was investigated for short stature. This had become progressively more marked with time. She has noticed an increasing immobility of the spine and backache but continues with an active job.

On examination height was $136.5 \mathrm{~cm} \quad(<3 \mathrm{rd}$ centile), weight $46.6 \mathrm{~kg}$ ( $3 \mathrm{rd}$ centile), head circumference $55.5 \mathrm{~cm}$ (50th centile), sitting height $68 \mathrm{~cm}(<-4 \mathrm{SD})$, and upper to lower height ratio 0.98 (mean 1.17). She had marked short stature with a severe thoracolumbar scoliosis. All spinal movements were limited with some discomfort on move-

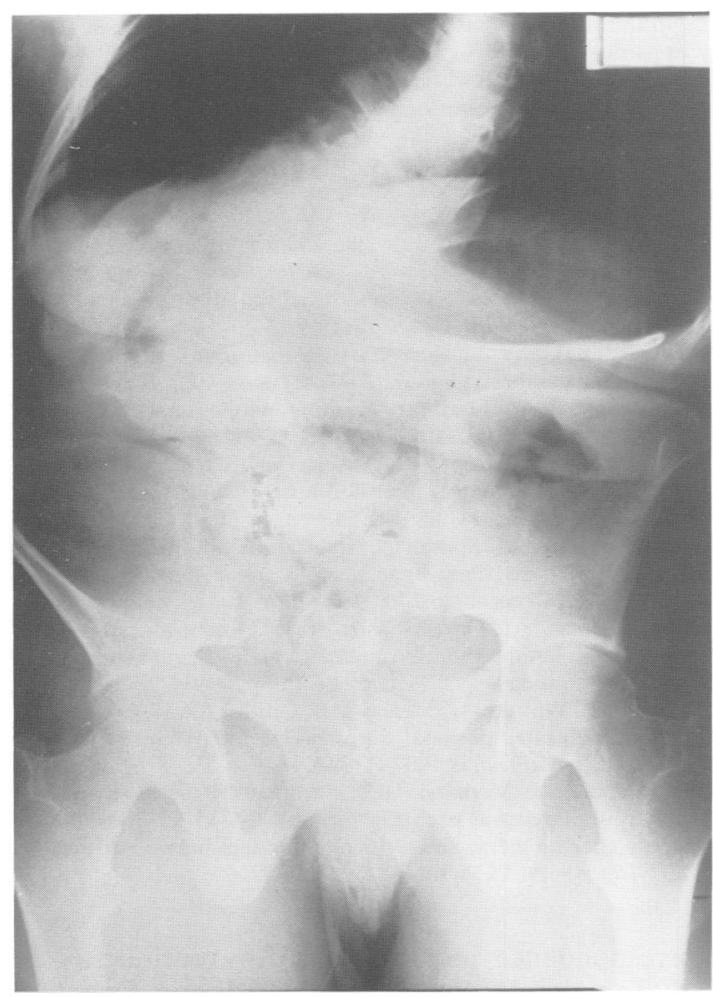

FIG 5 Spinal $x$ ray of $I I I \cdot 2$ showing severe scoliosis, convex to the right, centred at $L 1$.

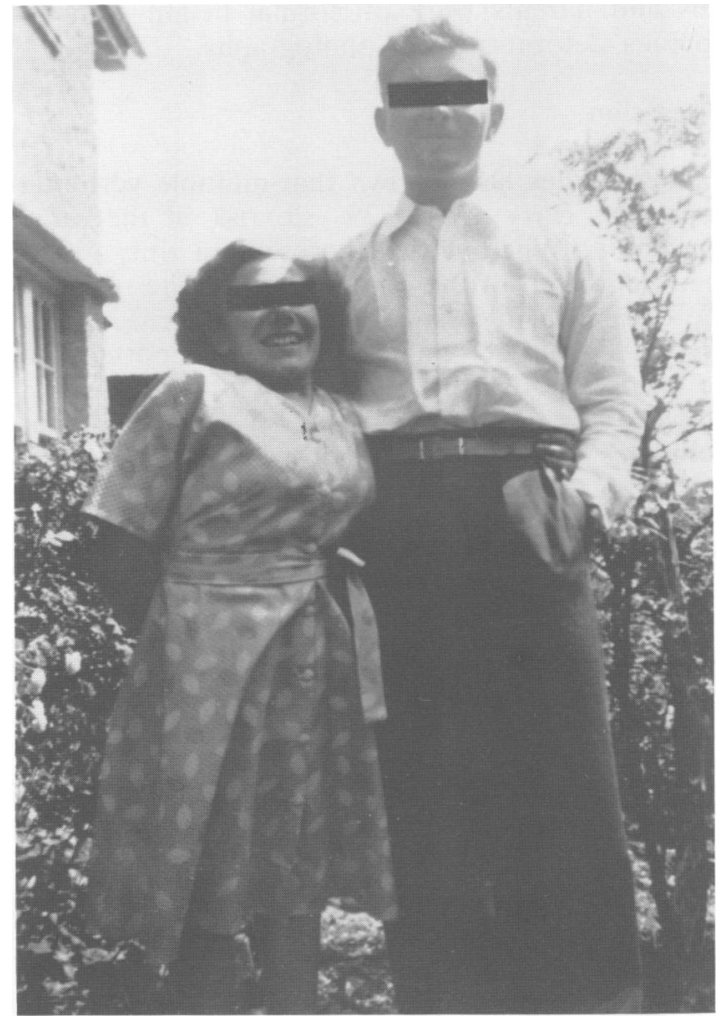

FIG 6 Patient 3 (II.5) in adult life (height $137 \mathrm{~cm}$ ) with her husband (height $175 \mathrm{~cm}$ ).

ment. Examination of her other joints and nervous system was normal.

Chromosome analysis showed a balanced translocation between chromosomes 9 and 15 (46,XX, $t(9 ; 15)(q 32 ; q 21 \cdot 2)) . X$ rays of the spine showed such a severe scoliosis that the individual vertebral architecture could no longer be determined (fig 5). No early films were available. Only 11 pairs of ribs could be seen bilaterally. There was some irregularity of shape and the position of the ribs was severely distorted, but this was clearly secondary to the severe spinal changes.

\section{PATIENT 3 (II.5)}

Patient 3 was born on 8.7.28 and is the grandmother of patient 1 . She died at the age of 46 years from pneumonia and chronic lung disease thought to be related to her marked scoliosis. Her adult height was $137 \mathrm{~cm}$ (fig 6). Again increasing back pain and immobility occurred with age.

No early history is available but she was the fifth child of unrelated parents in their late thirties. Her 
sibs and parents were of normal height with no obvious deformity from photographs.

\section{Discussion}

Family studies have shown that multiple vertebral anomalies carry a 2 to $3 \%$ sib risk of the same condition. ${ }^{1}$ Whether this represents a truly multifactorial effect, or the observed risk is the result of the occasional recessive or dominant gene, is not known. Few large families have been reported and no observed offspring risk is known for this group. However, both autosomal recessive and dominant pedigrees have been described with spondylocostal dysostosis. ${ }^{2-9}$ Whether this heterogeneous group is different from those with multiple vertebral anomalies is uncertain.

Spondylocostal dyostosis can be divided into a severe and mild group on clinical criteria, as discussed by Aymé and Preus. ${ }^{10}$

The severe autosomal recessive form, or JarchoLevin syndrome, ${ }^{11}$ with early death and gross thoracic deformity often associated with nonskeletal findings, is clearly distinguishable. Prenatal diagnosis by ultrasound at 20 weeks is also possible. $^{12}$

The findings in the milder form of spondylocostal dysostosis are limited to the spine and ribs. The severity of symptoms depends on the exact site and asymmetry of the vertebral changes which can occur throughout the spine. The rib changes, which include absence of ribs, fusion, and bifid ribs, are thought by many to be a secondary finding and to be dependent on the degree of thoracic involvement. ${ }^{39}$

The family in this report, therefore, should not be entirely excluded from the spondylocostal group on the basis of having limited rib changes. The most severe vertebral changes in patient 1 are in the lower thoracic, lumbar, and sacral region. The rib changes are confined to the 11 th rib. In the proband described by Rimoin et al, ${ }^{9} \mathrm{~T} 1$ and $\mathrm{T} 2$ were normal as were his first and second rib pairs. Patient 2 has only 11 pairs of ribs and their size and shape are distorted. We suggest that this family represents one end of the spectrum of spondylocostal dysostosis.

No clinical or radiological features consistently divide the dominant from the recessive pedigrees. The families described suggesting dominant inheritance have tended to present later and with short stature. $^{89}$ Our family would also fit into this pattern. Of six papers ${ }^{2-7}$ describing the mild autosomal recessive form, four ${ }^{367}$ mentioned that spinal or thoracic deformity was noted within the first six months of life in at least one sib. Perhaps this represents a division of severity between the two groups, but it is unlikely always to be consistent.
In general, where chromosomes have been studied in these families they have been normal. ${ }^{69}$ The $9 ; 15$ translocation in patient 2 is unlikely to be relevant in view of her son's normal karyotype. In 1963 , however, de Grouchy et al ${ }^{13}$ described a $14 ; 15$ translocation in a mother and daughter with multiple vertebral and rib anomalies, but the breakpoints were not given.

Until more families are described with pedigrees suggesting autosomal recessive or dominant forms of multiple vertebral anomalies, clinical factors to distinguish these groups will remain difficult, and it will not be possible to tell whether they represent a separate group from 'spondylocostal dysostosis'.

We would like to thank Dr Christine Hall for her valuable advice on the $x$ ray findings in this family. We also thank Miss Jo Bramfitt for typing the manuscript. IKT is funded by the Duchenne Muscular Dystrophy Group

\section{References}

1 Wynne-Davies R. Congenital vertebral anomalies: aetiology and relationship to spina bifida cystica. J Med Genet 1975;12:280-8.

2 Norum RA, McKusick VA. Costovertebral anomalies witt apparent recessive inheritance. Birth Defects 1969;V:326-9.

3 Castroviejo IP, Rodriguez-Costa T, Castillo F. Spondylo thoracic dysplasia in three sisters. Dev Med Child Neurof 1973;15:348-54.

4 Franceschini P, Grassi E, Fabris C, Bogetti G, Randaccio M. The autosomal recessive form of spondylocostal dysostosis. Radiology 1974;112:673-95.

5 Silengo MC, Cavallaro S, Franceschini P. Recessive spondylocostal dysostosis: two new cases. Clin Genet 1978;13:289-94.

6 Beighton P, Horan FT. Spondylocostal dysostosis in South African sisters. Clin Genet 1981;19:23-5.

7 David TJ, Glass A. Hereditary costovertebral dysplasia with malignant cerebral tumour. J Med Genet 1983;20:441-4.

8 Van Der Sar A. Hereditary multiple hemivertebrae. Doc Med Geographica Tropica 1952;4:23-8.

${ }^{9}$ Rimoin DL, Fletcher BD, McKusick VA. Spondylocostal dysplasia. A dominantly inherited form of short-trunked dwarfism. Am J Med 1968;45:948-53.

10 Aymé S, Preus M. Spondylocostal/spondylothoracic dysostosis: the clinical basis for prognosticating and genetic counselling. Am J Med Genet 1986;24:599-606.

11 Pérez-Comas A, Garcia-Castro JM. Occipito-facial-cervicothoracic-abdomino-digital dysplasia: Jarcho-Levin syndrome of vertebral anomalies. J Pediatr 1974;85:388-91.

12 Tolmie JL, Whittle MJ, McNay MB, Gibson AAM, Connor JM. Second trimester prenatal diagnosis of the Jarcho-Levin syndrome. Prenat Diagn 1987;7:129-34.

13 De Grouchy J, Mlynarski JC, Maroteaux P, et al. Syndrome polydysspondylique par translocation $14-15$ et dyschondrostéose chez un même sujet. Ségrégation familiale. CR Acad Sci [D] (Paris) 1963;256:1614-5.

Correspondence and requests for reprints to $\mathrm{Dr}$ I K Temple, Department of Paediatric Genetics, Institute of Child Health, 30 Guilford Street, London WC1N 1EH. 